\title{
Title: Transit Time Distribution Based on the ECCO-JPL Ocean Data Assimilation
}

Authors: Takamitsu Ito(1*) and Ou Wang(2)

\section{Affiliations:}

1. School of Earth and Atmospheric Sciences, Georgia Institute of Technology, Atlanta, Georgia, U.S.A.

2. Jet Propulsion Laboratory, California Institute of Technology, California, U.S.A.

*Corresponding author Email: taka.ito@eas.gatech.edu

\begin{abstract}
:
Oceanic water mass is a mixture of waters with varying ages, and the transit time distribution (TTD) measures its age spectrum. We construct a model-based TTD using the data-constrained circulation fields from the ECCO-JPL ocean data assimilation, and test it against the observed and directly simulated distribution of pCFC-11 from the Pacific and Atlantic basins. The ECCOJPL circulation provides overall reliable estimates of the upper ocean ventilation rates suitable for biogeochemical studies. Observed distributions of pCFC-11 in the upper ocean thermocline are well reproduced by the convolution integral of the model-based TTD (mean bias $<6 \%$, spatial correlation $>0.87$ ) but there are significant regional biases in particular near the base of the thermocline and in the deep water formation regions. The model underestimates the deep pCFC$11(>2,000 \mathrm{~m})$ in the North Atlantic and in the Southern Ocean. The ratio between the mean and the spread of the age spectrum $(\Gamma / \Delta)$ is close to unity (mean=1.04, median=0.99) in the ventilated thermocline of the Pacific basin but there are significant regional variations of the ratio.
\end{abstract}


Key words: Transit time distribution, ocean data assimilation, CFC-11

\section{Introduction}

Ventilation of the upper ocean thermocline plays crucial role in the biogeochemical cycling and the oceanic uptake of heat and carbon dioxide from the atmosphere [Sabine et al., 2004]. Formation of thermocline waters occurs during winter-time convection transferring surface properties into the interior ocean. Distribution of inert transient gas tracers in the interior ocean reflects the surface concentration at the time and location of the water mass formation [Jenkins, 1977; Warner et al., 1996], and can be used to infer when the water was last in contact with the atmosphere. Observed transient tracers in conjunction with the known history of its atmospheric concentrations can be used to calculate the age of water. However, oceanic tracers are influenced by the effect of turbulent mixing while transported in the ocean, which complicates the interpretation of the transient tracers [Waugh et al., 2003]. For example, misfits have been observed between water age estimated from the concentrations of different tracers with different histories of atmospheric concentrations [Mecking et al., 2004]. Such misfits can be reconciled by considering the effect of turbulent mixing in setting the water mass composition with a range of water ages [Hall and Plumb, 1994; Beining and Roether 1996; Haine and Hall 2002; Waugh et al., 2003].

There is no single age for a water mass which is a mixture of waters ventilated at different times [Waugh et al., 2003]. Transit Time Distribution (TTD) can represent the water mass composition with a spectrum of water ages. It is a useful diagnostic of the ocean ventilation and 
is widely applied to biogeochemical tracer studies [Holzer et al., 2010; Hunn et al., 2013;

Khatiwala et al., 2009; Klatt et al., 2002; Sonnerup et al., 2013; 2015; Stanley et al., 2012;

Steinfeldt and Rhein, 2004; Tanhua et al., 2007; 2009]. TTD is mathematically expressed as the Greens function $(G)$ forced by a uniform impulse at the surface. Consider a spatially uniform, time varying surface boundary condition $X_{0}(t)$, which may be analogous to the partial pressure of inert trace gases such as CFCs. The resulting tracer distribution can be written as

$$
X(\mathbf{r}, t)=\int_{-\infty}^{t} X_{0}\left(t^{\prime}\right) G\left(\mathbf{r}, t, t^{\prime}\right) d t^{\prime}
$$

which integrates the past influence from the boundary weighted by the Greens function, $G$, [Waugh et al., 2003]. Thus, once $\mathrm{G}$ is determined, any inert tracer distribution (such as pCFC-11) forced by the surface boundary condition can be calculated by performing the convolution integral (1). This approach can be extremely efficient computationally relative to time-stepping the discretized advection-diffusion equation for each tracer with different boundary conditions. Furthermore, the statistics of the TTD itself provides meaningful metric for the ventilation of the water masses. The first and second moment of the TTD determine the mean age $(\Gamma)$ and the spread of the age spectrum $(\Delta)$.

The overarching goal of this study is to obtain an accurate description of the TTD for the contemporary ocean general circulation. Theoretically TTD for the one-dimensional advection diffusion tracer transport equation takes the form of an Inverse Gaussian (IG) function involving only two coefficients $(\Gamma, \Delta)$ [Waugh et al., 2003]. Previous observational studies constrained the one-dimensional TTD by fitting the inverse Gaussian to the measured concentrations of chemical 
tracers along an isopycnal surface. In practice it is often assumed that the two unknown parameters $(\Gamma, \Delta)$ are related by a simple, constant ratio. Empirically, the magnitude of $\Gamma$ and $\Delta$ may be related since an older water may have had more time to mix. Based on the observations from the North Atlantic, Waugh et al. (2004) suggested the ratio is approximately unity, which is applied and evaluated favorably in oceanographic research [e.g. Tanhua et al., 2007; 2009; Sonnerup et al., 2013; Sonnerup et al., 2015; Stanley et al., 2012; Steinfeldt and Rhein, 2004]. This approach is attractive as it only requires a single tracer observation to determine a TTD but it is subject to errors due to the prescribed shape of the IG function and the assumed relationship between $\Gamma$ and $\Delta$. Holzer et al., (2010) independently estimated the TTD using the Maximum Entropy method based on the hydrographic observations, and revealed that the IG assumption can break down in many regions.

Alternatively, numerical models of ocean circulation and tracer transport can be used to construct Greens functions [Gruber et al., 2009; Khatiwala et al., 2001; Maltrud et al., 2010; MikaloffFletcher et al., 2006; Peacock and Maltrud, 2006; Primeau and Holzer, 2006]. The successful application of the model-based Greens function obviously depends on the ability of the model to accurately reproduce the three-dimensional circulation fields. Recent advances in ocean data assimilation provide dynamically consistent reconstruction of the time evolving ocean circulation fields [Wunsch et al., 2009; DeVries and Primeau 2011], which can be used to calculate a global, three-dimensional TTD. DeVries and Primeau (2011, hereafter DP11) recently constrained a dynamically-consistent three dimensional ocean circulation fields using hydrographic and tracer observations, and provided detailed analysis of the ventilation of deep waters and associating circulation timescales. In this study, we take a similar approach where we attempt to determine a 
TTD by performing a numerical simulation using a data-constrained, three-dimensional ocean circulation fields. We subsequently test the model-based TTD against independent tracer observations to ensure that resulting TTD is realistic. The key difference between this study and DP11 is that this study uses time-varying (1993-present) circulation fields based on the ECCOJPL Ocean Data Assimilation product whereas DP11 estimated time-averaged circulation fields based on the climatological hydrographic and tracer observations. While we show results from the full water column, our study is primarily suitable for characterizing the upper ocean ventilation considering the multi-decadal assimilation period. In contrast, DP11 included radiocarbon data and its main focus was to constrain the deep ocean ventilation.

The structure of the paper is as follows. In section 2, we briefly describe the ECCO-JPL Ocean Data Assimilation and the circulation fields used to construct the TTD. We also perform the direct simulation of CFC-11 using the same circulation fields in order to test the ability of the TTD approach to reconstruct the CFC distribution. In section 3, we present the model validation, and examine the results on the mean age and its distribution in the main thermocline of the North Pacific, North Atlantic and the Southern Ocean. In section 4, we discuss the implications of our results and conclude.

\section{Model description and experimental design}

\subsection{Model source and ECCO-JPL Ocean Data Assimilation}


We use the data-constrained circulation fields from the ECCO-JPL Ocean Data Assimilation where a primitive equation ocean general circulation model is constrained by the state-of-the-art assimilation system. ECCO-JPL uses an ocean circulation model based on the Massachusetts Institute of Technology General Circulation Model (MITgcm) with a near-global domain $\left(79.5^{\circ} \mathrm{S}-78.5^{\circ} \mathrm{N}\right)$. Model horizontal resolution is $1^{\circ}$, telescoping to $0.3^{\circ}$ meridionally within $20^{\circ}$ of the equator. The vertical resolution is $10 \mathrm{~m}$ in the upper $150 \mathrm{~m}$ with total 46 vertical levels (deepest sea bottom is set to $5815 \mathrm{~m}$ ). The model is forced by National Centers for Environmental Prediction (NCEP) reanalysis products (12-hourly wind stress along with daily diabatic air-sea fluxes) with time-means replaced by those of the Comprehensive Ocean-Atmosphere Data Set (COADS) [see Lee et al., 2002 for detailed model description and setup]. Mesoscale eddy fluxes are parameterized using isopycnal thickness diffusion scheme [Gent and Mcwilliams, 1990] with spatially varying diffusivity. The isopycnal stirring of tracer [Redi, 1982] is also implemented with the same spatially varying diffusivity. To parameterize the mixing processes in the mixed layer, we employ the K-Profile Parameterization (KPP) mixed-layer formulation [Large et al., 1994].

Sea level anomalies (RADS version of TOPEX/Poseidon, Jason-1, and Jason-2 available at http://rads.tudelft.nl/rads/rads.shtml) and in-situ temperature profiles from NCEP (available at $\mathrm{ftp}: / / \mathrm{ftp} . \mathrm{emc}$. ncep.noaa.gov/cmb/Products/xbt_ofmt/) are assimilated into the model using a Kalman filter [Fukumori, 2002]. The filter estimates consist of large-scale adiabatic adjustments of the model state, but are not dynamically consistent. Therefore, smoothed wind is obtained by the Rauch-Tung-Striebel fixed-interval smoother [Fukumori, 2002] that corrects inaccuracies in the wind forcing. Model states and along-isopycnal mixing coefficients (smoother estimates) for 
1993 to 2013 driven by the smoothed winds are employed in this study. The temporal evolution

of the smoother estimates satisfies model equations and thus can be used for budget analyses and offline tracer simulations. The general circulation and water properties of ECCO-JPL products are reasonably consistent with observational data as shown in previous studies [Lee and Fukumori, 2003; Lee et al., 2002; Qu et al., 2013; Wang et al., 2004].

\subsection{Numerical simulation of Transit Time Distribution}

The passive tracer equation is numerically integrated in the offline mode using climatological circulation, temperature, salinity and mixing coefficients based on the ECCO-JPL circulation fields. The version of ECCO-JPL product used in this study covers 21 years from 1993 to 2013, and the climatological mean fields are calculated by dividing one year into 37 segments where each segment is approximately 10 -day long and taking averages over the 21 -year period. Since we do not integrate the ocean dynamics, the numerical integration is computationally efficient. Using a single linux computing server with 32 processing cores, it takes approximately half an hour to perform one-year long integration with a time step of 2 hours.

The numerical simulation of TTD is typically based on the application of a delta-function boundary condition on the upper boundary. In practice, the impulse must be applied over a finite interval of time, normally chosen to be one year to average out one full seasonal cycle [Khatiwala et al., 2001]. In this study we take an alternative approach to simulate the integral of the TTD. A single passive tracer, $C$, is numerically integrated in order to determine the temporal integral of the TTD, G(r, $\tau)$. One can numerically integrate the passive tracer equation initialized with zero concentration for the entire domain with a spatially-uniform constant surface boundary 
concentration of $C(z=0)=1$. The time history of the tracer concentration $\mathrm{C}(\mathbf{r}, \mathrm{t})$ is recorded as the output of the model. Theoretically, $\mathrm{C}(\mathbf{r}, \mathrm{t})$ is a cumulative distribution function of the transit time (hereafter, CTTD). Subsequently, the time derivative of $C(r, t)$ can be evaluated to determine the TTD, which is equivalent of differentiating Eq (1).

$$
G(\mathbf{r}, t)=\frac{\partial C(\mathbf{r}, t)}{\partial t}
$$

This approach is simpler and preferable in the context of numerical simulation rather than directly simulating $G(\boldsymbol{r}, t)$ by imposing a delta-function impulse to the surface water. The boundary condition for the CTTD is almost trivial to implement (setting $C=1$ in the surface grid cell), and the post-processing of the model output only requires a simple differentiation (Eq. 2). We find this approach preferable as it does not require arbitrary choice for the width of delta function in the surface boundary condition.

The climatological annual cycle is repeated to integrate the tracer equation for 2,000 years, adequate for the upper ocean ventilation. The resulting three-dimensional fields of CTTD are saved as annual mean field. Then the TTD is calculated by taking the finite difference of the CTTD. The post-processing of the data and the differentiation of CTTD is performed using MATLAB on a workstation, and the resulting TTD is recorded for later analysis.

\subsection{Evaluating the calculated Transit Time Distribution against CFC-11 data}

We can calculate the distribution of a transient tracer, pCFC-11, in the interior ocean by the convolution integral (Eq. 1). In the limit case where the gas exchange is sufficiently strong 
relative to the ocean circulation and mixing, we can assume that the surface $\mathrm{CFC}-11$ concentration is in saturation with the overlying atmosphere. Scale analyses suggest that most surface waters are indeed close to the saturation with atmospheric pCFC-11, but this likely overestimate the oceanic uptake since the finite timescale of air-sea gas transfer keeps the surface water slightly undersaturated [Haine and Richards, 1995; Ito et al., 2004; Hall et al., 2004; Khatiwala et al., 2009]. Assuming the saturation at the surface, we may predict the distribution of CFC-11 using the TTD following Eq (1).

$$
p C F C 11_{o c n}(\mathbf{r}, t)=\int_{0}^{+\infty} p C F C 11_{a t m}(t-\tau) G(\mathbf{r}, \tau) d \tau
$$

where the observed atmospheric partial pressure of CFC-11 $\left(p C F C 11_{\text {atm }}\right)[$ Bullister, 2015] can be used to numerically evaluate the integral. The solubility of CFC-11 in the seawater $(K c)$ is a known function of temperature [Warner and Weiss, 1985], so the product of oceanic pCFC-11 $\left(p C F C 11_{\text {ocn }}\right)$ and $K c$ can also provide an estimate for the in-situ concentration of CFC-11. Anthropogenic emission has been the only source of CFC-11 to the atmosphere, and the level of pCFC11 atm prior to 1930 s is negligible. Thus an 80 -year integration of Eq (3) would be sufficient. The resulting distribution of CFC-11 can then be compared to the observations.

This approach makes several important assumptions. We assume the climatological circulation for the practical application of the TTD method. It also assumes complete saturation at the airsea interface. This is known to overestimate the oceanic uptake in the region of deep mixed layer [Haine and Richards, 1995; Mecking et al., 2004]. To evaluate the impact of these assumptions, we also perform direct numerical simulation of CFC-11 using the circulation fields from the 
ECCO-JPL product. In this case, the model is initialized with zero concentration in 1930, and the equation for CFC-11 is numerically integrated based on the climatological circulation fields till the end of 1992. From the beginning of 1993 we use the realistic, time-varying circulation fields replacing the climatological fields. The air-sea gas flux is calculated following the parameterization of gas transfer coefficient by Wanninkhof [1992] forced by the observed atmospheric partial pressure of CFC-11 modulated by the fractional seaice cover $\left(f_{\text {ice }}\right)$. This approach of direct numerical simulation does not assume the saturation state at the surface and the surface concentration evolves according to the time-varying circulation. The resulting distribution of $\mathrm{pCFC} 11_{\mathrm{ocn}}$ is compared to the observation and the TTD-based estimates to evaluate the effects of the interannual variability and the surface boundary condition. 


\section{Results}

\subsection{Model evaluation}

We first validate our calculation of CFC-11 against the observations. The results from the direct numerical simulation as well as the TTD-based estimates are compared to the recent WOCE/Clivar ocean transects in Fig 1-4. All the comparisons are performed after 1992 overlapping the data assimilation period of the ECCO-JPL products. The model captures the observed magnitude and the spatial structure of CFC-11 reasonably well. Table 1 shows the quantitative assessment of the mean bias and spatial correlation between the modeled and observed pCFC11.

\section{[Figure 1]}

\section{[Table 1]}

Repeat P16N covers the central North Pacific from the equatorial to the subpolar latitudes (Fig 1). At a first glance, both the direct simulation and the TTD-based estimates capture the shallow tropical thermocline where the strong vertical gradient of pCFC-11 is represented at approximately $200 \mathrm{~m}$ depth in the vicinity of the equator. The bowl of well-ventilated warm water in the subtropical thermocline is also well represented with its depth and the magnitude of pCFC-11. Towards the subpolar latitudes, the vertical extent of the pCFC-11 decreases rapidly, again capturing the observations reasonably well. The detailed comparison (Fig 1def) shows where the model fails to reproduce the observed pCFC-11 distribution. The direct simulation and the TTD-based estimates overestimate the pCFC-11 near the base of the thermocline (Fig 1de). 
The spatial patterns of the model error (as shown in Fig 1d and 1e) are relatively similar to one another, which likely reflect the error in the mean circulation fields. In another words, Fig $1 \mathrm{~b}$ and $1 \mathrm{c}$ are relatively similar to one another, suggesting that the two major assumptions in the TTD approach (i.e. saturation at the surface and lack of interannual variability) did not significantly impact on the overall spatial pattern of CFC-11 in this particular section. Quantitatively, both direct simulation and TTD-based estimates slightly overestimate the pCFC-11 with the mean biases of $4.39 \%$ and $1.71 \%$ respectively. Spatial correlations are very high, about 0.98 for both cases. The TTD-based estimates are based on the climatological mean circulation fields. Fig $1 \mathrm{f}$ compares the simulation and the TTD-based estimate, showing the spatially-varying signs of the pCFC-11 difference fields likely due to the re-distribution of tracer anomalies by the interannually varying circulation fields in the direct simulation.

Repeat P16S covers the central South Pacific from the Southern Ocean to the subtropics (Fig 2). The meridional structure is captured reasonably well with the strongly tilted thermocline associated CFC-11 distribution in the Southern Ocean [Ito et al., 2004]. The overall magnitude and the vertical penetration are captured by the direct numerical simulation (Fig $2 \mathrm{~b}$ ) as well as the TTD-based estimate (Fig 2c). However, some model biases are evident in the Southern Ocean. The model tends to overestimate the vertical extent of the high CFC water in the Antarctic Surface Water (south of $50^{\circ} \mathrm{S}$ ) for this specific transect. The similar error structure between the direct simulation and the TTD-based estimates (Fig 2de) indicate the error in the mean circulation. Both the direct simulation and the TTD-method underestimate the deepest ventilation of CFC below $3,000 \mathrm{~m}$ at about $60-65^{\circ} \mathrm{S}$, again indicative of the mean circulation error. The spatial structure of the model error consists of overestimation at high latitudes 
(poleward of $50^{\circ} \mathrm{S}$ ) and underestimation at subtropics (equatorward of $50^{\circ} \mathrm{S}$ ). These two opposing errors compensate one another in the mean bias of about $5 \%$. However, the regional error is much greater in magnitude ( $>60 \mathrm{pptv})$. Fig $2 \mathrm{f}$ compares the simulation and the TTDbased estimate, showing the spatially-varying signs of the pCFC-11 difference fields likely due to the re-distribution of tracer anomalies by the interannually varying circulation fields.

\section{[Figure 2]}

Repeat P18 covers the eastern South Pacific from the Southern Ocean to the equatorial regions (Fig 3). The observed thermocline structure is reproduced from the bowl of thermocline in the subtropics to the very shallow tropical thermocline. Similar to the other Pacific sections, the overall magnitude and the vertical structure are well captured by the direct numerical simulation (Fig 3b) as well as the TTD-based estimate (Fig 3c). In particular, the model captures a detectable level of CFC-11 reaching below 2,000m around $50^{\circ} \mathrm{S}$. Overall, the similar error structure between the direct simulation and the TTD-based estimate (Fig 3de) indicate the error in the mean circulation. Similar to other sections, both direct simulation and TTD-based estimates slightly overestimate the pCFC-11 with the mean biases of about $3 \%$ while the regional biases can be larger. The most significant regional biases are found near the base of the thermocline, which is also similar to other Pacific transects. The spatial correlations are approximately 0.98 for both cases.

[Figure 3] 
Repeat A16N covers the North Atlantic from the subtropics to the subpolar regions (Fig 4). The model shows elevated subpolar pCFC-11 in the intermediate depth $(1,000-2,000 \mathrm{~m})$ poleward of $50^{\circ} \mathrm{N}$ indicating that these waters are ventilated too strongly (Fig 4abc). Both the direct numerical simulation and the TTD-method overestimate the ventilation at the intermediate depth $(1,000-2,000 \mathrm{~m})$ at the expense of underestimating in the upper water column $(<1,000 \mathrm{~m})$ in the subpolar region north of $50^{\circ} \mathrm{N}$. The direct simulation and the TTD-method also underestimate in the deep water below 2,000m depth. Similar to the Pacific transects, the common biases in the direct simulation and the TTD-based estimate (Fig 4de) indicate that the dominant error is in the mean circulation. Comparing the direct numerical simulation and the TTD-based estimates (Fig $4 \mathrm{f})$, the former shows relatively lower pCFC- 11 by $10-15 \%$ at the subpolar latitudes. This is consistent with the magnitude of undersaturation reported in earlier studies [Haine and Richards, 1995]. ECCO-JPL does not include sea-ice component, and also the model domain does not include the Arctic Ocean, which may be an important reason for the biases in simulating deeper water masses at high latitudes. Again, the direct simulation and the TTD-based estimates slightly overestimate the pCFC- 11 with the mean biases of about $0.1 \%$ and $5 \%$ respectively, and the spatial correlations are about 0.9 for both cases.

\section{[Figure 4]}

The regional features of the CFC-11 ventilation can be summarized as follows.

- Ventilation of tropical and subtropical thermocline including the equatorial Pacific is represented reasonably well in the offline ECCO-JPL circulation. 
- The mean bias is generally about $6 \%$ or smaller, and the spatial correlation is equal to or higher than 0.87. Significant regional biases are found near the base of the ventilated thermocline.

- Direct numerical simulation and TTD-based estimates of the CFC ventilation produced similar results in the tropical and subtropical thermocline.

- For the deep water masses, this model underestimates the deep ventilation in the Southern Ocean and the North Atlantic. The ventilation of intermediate waters is overestimated in the North Atlantic.

- In the Antarctic region, the CFC ventilation is overestimated in the upper ocean $(<500 \mathrm{~m})$.

\subsection{Evaluating moments of Transit Time Distribution}

We further investigate the simulated TTD in the thermocline and intermediate waters. In particular we investigate the North Atlantic Sub-Tropical Mode Water (NASTMW) on the isopcyanl surface $\sigma_{\theta}=26.5$ and the North Pacific Sub-Tropical Mode Water (NPSTMW) on the isopcyanl surface $\sigma_{\theta}=25.2$. These water masses are well sampled at the ocean time series station. In the North Atlantic, Bermuda Atlantic Time-Series study (BATS) is located at approximately $31^{\circ} \mathrm{N}, 64^{\circ} \mathrm{W}$. NASTMW forms a thermostad in the subtropical North Atlantic at the temperature of $18^{\circ} \mathrm{C}$. In the North Pacific, Hawaii Ocean Time-Series study (HOT) is located at approximately $22^{\circ} \mathrm{N}, 158^{\circ} \mathrm{W}$. The TTD as well as its first moments are evaluated for the STMWs at the location of BATS and HOT studies (Fig 5ab).

[Figure 5] 
The mean age $(\Gamma)$ of NASTMW at the location of BATS study is approximately 3.45 years, and that of NPSTMW at the location of HOT study is approximately 4.82 years. The integration of the first moment slowly drifts even after several centuries of integration due to the long tail of the TTD. However, approximately after 100 years of integration, the magnitude of the drift becomes small $\mathrm{O}\left(\mathrm{a}\right.$ few $\%$ century $\left.^{-1}\right)$. The square root of the second moment $(\Delta)$ at the location of BATS study is approximately 7.66 years and that of HOT study is approximately 4.54 years. In oceanographic research, it is difficult to determine the exact shape of TTD based on observations alone, and TTDs are often approximated using Inverse Gaussian (IG) functions. Fig $5 \mathrm{ab}$ evaluates how well IG functions can approximate the modeled TTD of the three-dimensional ocean model in specific regions. We calculated IG functions for the NASTMW and NPSTMW based on the modeled TTD (Fig 5ab). The thin solid lines (marked as IG) are calculated using both the first and second moments $(\Gamma, \Delta)$ of the modeled TTD whereas the thin dash lines (marked as IG, $\mathrm{Pe}=1$ ) are calculated using the modeled $\Gamma$ assuming $\Delta=\Gamma$ (equivalent of $\mathrm{Pe}=1$ in one-dimensional problem). IG functions are analytic solutions to the one-dimensional advection diffusion problem, and are not expected to exactly reproduce the TTDs in the three-dimensional problem. In this specific example, even the perfect knowledge of both the first and the second moment does not improve the fit between the IG function and the modeled TTD indicating the limitation of the one-dimensional theory.

Figure 5cd shows the TTD of the intermediate waters $(1,000 \mathrm{~m}$ depth) in the North Atlantic, the North Pacific and the Southern Ocean. The locations of TTDs from the North Atlantic and the North Pacific are the same as Figure 5a. We also include the TTD at 1,000m in the Drake Passage $\left(60^{\circ} \mathrm{S}, 60^{\circ} \mathrm{W}\right)$. In the North Atlantic, the water at $1,000 \mathrm{~m}$ depth is close to the core of the 
Antarctic Intermediate Water (AAIW), and the simulated TTD exhibits a peak at 61 years. In the North Pacific, the water at this depth is close to the core of the North Pacific Intermediate Water. There are two broad peaks in the TTD (Fig 5d); the first peak is at about 203-208 years and the second peak is at about 1651-1660 years. The water at this depth is likely a mixture of intermediate and deep waters with two distinct ventilation timescale. At shallower depth, the TTD is dominated by the younger peak, and in contrast, at depth the TTD is dominated by the older peak. The TTD from the Drake Passage exhibits the youngest peak at 21 years but the it also has a long tail (Fig 5c). The Drake Passage is close to the region of AAIW formation, which may explain the relatively young peak, but the water at 1,000m depth may be closer to the Upper Circumpolar Deep Water (UCDW) which may be a mixture of the intermediate and deep waters from the southeastern Pacific and the south Atlantic basins. The moments of TTDs at $1,000 \mathrm{~m}$ depth from all the basins drift significantly even after 2,000 years of integration, and a longer integration is necessary for them to converge.

Figure 6 shows the spatial pattern of the isopycnal depth and the mean age $(\Gamma)$ on the $\sigma \theta=25.2$ surface. The first moment was approximated with an integration period of 200 years. While accurate determination of $\Gamma$ requires integration over an infinite time period, considering that the magnitude of the TTD rapidly decays beyond 10 years, the choice of a 200 -year integration period is sufficient to yield a reasonable estimate in shallower waters. Furthermore, the spread of the $\operatorname{TTD}(\Delta)$ can also be estimated by calculating the second moment. Again it requires the truncation of the infinite integral.

\section{[Figure 6]}


Figure 7 shows the map of $\Delta$ and the ratio between $\Gamma$ and $\Delta$. The magnitude of $\Delta$ can be interpreted as the effect of mixing broadening the age spectrum, thus the ratio measures the relative importance of advection and diffusion. In the Pacific basin, the mean and median of $\Gamma / \Delta$ are 1.04 and 0.99 , very close to unity on the isopycnal $\sigma \theta=25.2$. However, its spatial pattern is not uniform. Near the isopycnal outcrop in the North Pacific at about $40^{\circ} \mathrm{N}$, the magnitude of $\Gamma / \Delta$ is less than 0.5 indicating relatively strong influence of tracer mixing there. In the interior gyre at about $20^{\circ} \mathrm{N}$ and south of $20^{\circ} \mathrm{S}, \Gamma / \Delta$ is higher than 1.5 , indicating relatively strong influence of tracer advection. It is relatively small in the tropics (0.5-1) except for within $\pm 2^{\circ}$ latitude of the equator and the eastern tropical North Pacific where the magnitude exceeds 1.

\section{[Figure 7]}

\section{Discussion and conclusion}

We estimated the transit time distribution (TTD) using the ECCO-JPL Ocean Data Assimilation products, and tested it against the distribution of a transient tracer, CFC-11, from the WOCE/CLIVAR repeat hydrography program. Specifically, the model-based TTD is tested against the data from the four cruises including P16N, P16S, P18 and A16N from 1990s to 2000s. Overall we found that ventilation of upper ocean thermocline in the tropics and subtropics is accurately represented in the offline simulation as well as the TTD-based estimates. For deep water masses, this model underestimates the ventilation of Antarctic Bottom Water and

overestimates the ventilation of North Atlantic Deep Water. Both the first moment, i.e. the mean 
age $(\Gamma)$, and the second moment of TTD that is proportional to the spread of the age spectrum $(\Delta)$ have been calculated. In the one-dimensional advection-diffusion equation, the ratio between the mean $(\Gamma)$ and the spread $(\Delta)$ is the Peclet number $(\mathrm{Pe})$, measuring the relative importance of advection and diffusion. It is typically assumed that Pe is close to unity in typical oceanographic conditions [Waugh et al., 2004]. We confirmed this assumption on the basin scale averages, however there are significant regional differences that the magnitude of Pe can range from 0.5 to 2.5. Our results are generally consistent with the previous study explicitly testing the ability of the TTD to reproduce CFC-like tracer in the global thermocline [Peacock and Maltrud, 2006], showing a good agreement between direct simulation and the convolution integral of the TTD in the ventilated thermocline. Our work confirms that the ECCO-JPL-based TTD can reproduce observed pCFC-11 distributions with very good accuracy (mean bias $<6 \%$, spatial correlation $>$ 0.87) for the four ocean transects we examined.

The TTD developed in this study reflects the averaged ocean circulation fields for the assimilation period of ECCO-JPL products from 1993 to 2013, and is only validated against the in-situ measurements of $\mathrm{pCFC} 11_{\mathrm{ocn}}$, which primarily reflects the upper ocean ventilation during the second half of the $20^{\text {th }}$ century. While the model exhibits very high skill in capturing the upper thermocline ventilation over this period, there could be biases in the ventilation of deeper waters. The model-data differences in the southern mid and high latitudes for P16S and P18 are similar in pattern and magnitude to the differences shown in Waugh et al. (2013). We interpreted that this is primarily a model bias, but it leaves a possibility that the model-data misfit may be due to the multi-decadal change in the ventilation of the Southern Ocean thermocline. Observed change in the thermocline CFCs may reflect the changing ventilation rates as suggested by 
Waugh et al. (2013) but the relatively short period of ECCO-JPL data assimilation (1993-2013) cannot capture such a multi-decadal change. Also, for longer-lived tracers, the convolution integral must be performed over a long time, and additional validation would be necessary using a different tracer such as radiocarbon [DeVries and Primeau, 2010]. There is no guarantee that our TTD would be the best choice for such long-term applications since our physical circulation fields are meant to reproduce the conditions after 1993.

With above limitations in mind, the ECCO-JPL based TTD has a range of potential applications. Much of the anthropogenic carbon remains in the upper ocean thermocline, and our TTD may be suitable for calculating the anthropogenic carbon either directly or as a prior estimate for inverse calculations [DeVries, 2014; Khatiwala et al., 2009; Waugh et al., 2006]. Another important application can be the quantification of upper ocean biogeochemical rates such as subsurface

respiration [Feely et al., 2004; Sonnerup et al., 2013; Sonnerup et al., 2015; Stanley et al., 2012] and production of nitrous oxide [Freing et al., 2012; Yamagishi et al., 2005]. The nutrient and gas tracers indicate cumulative changes integrating the source/sink terms over the ventilation timescale. The age of water is therefore necessary to translate the cumulative changes to the rates. The source code, model configuration, and the resulting TTD are archived in the corresponding author's institutional server and is available upon request.

\section{Acknowledgement}

TI is supported by the U.S. National Science Foundation Grant Number OCE-1357373 and PLR1142009. Part of this work was carried out at the Jet Propulsion Laboratory, California Institute 
of Technology, under a contract with the National Aeronautics and Space Administration (NASA). 


\section{References}

Beining, P., Roether, W., (1996). Temporal evolution of CFC 11 and CFC 12 concentrations in the ocean interior. Journal of Geophysical Research, 101, 16,455-16,464.

Bullister, J. L. (2015), Atmospheric Histories (1765-2015) for CFC-11, CFC-12, CFC-113, CC14, SF6 and N2O. Rep., Carbon Dioxide Information Analysis Center, Oak Ridge National Laboratory, US Department of Energy, Oak Ridge, Tennessee. .

DeVries, T. (2014), The oceanic anthropogenic CO2 sink: Storage, air-sea fluxes, and transports over the industrial era, Global Biogeochem Cy, 28(7), 631-647, doi:10.1002/2013gb004739.

DeVries, T., and F. Primeau (2010), An improved method for estimating water-mass ventilation age from radiocarbon data, Earth and Planetary Science Letters, 295(3-4), 367-378, doi:10.1016/j.eps1.2010.04.011.

DeVries, T., and F. Primeau (2011), Dynamically and Observationally Constrained Estimates of Water-Mass Distributions and Ages in the Global Ocean, J Phys Oceanogr, 41(12), 2381-2401, doi:10.1175/JPO-D-10-05011.1.

Feely, R. A., C. L. Sabine, R. Schlitzer, J. L. Bullister, S. Mecking, and D. Greeley (2004), Oxygen utilization and organic carbon remineralization in the upper water column of the Pacific Ocean, J Oceanogr, 60(1), 45-52, doi:10.1023/B:JOCE.0000038317.01279.aa.

Freing, A., D. W. R. Wallace, and H. W. Bange (2012), Global oceanic production of nitrous oxide, Philosophical Transactions of the Royal Society B-Biological Sciences, 367(1593), 12451255, doi:10.1098/rstb.2011.0360.

Fukumori, I. (2002), A partitioned Kalman filter and smoother, Mon Weather Rev, 130(5), 13701383, doi:10.1175/1520-0493(2002)130<1370:apkfas>2.0.co;2.

Gent, P. R., and J. C. Mcwilliams (1990), Isopycnal Mixing in Ocean Circulation Models, J Phys Oceanogr, 20(1), 150-155, doi:10.1175/1520-0485(1990)020<0150:Imiocm>2.0.Co;2.

Gruber, N., et al. (2009), Oceanic sources, sinks, and transport of atmospheric CO2, Global Biogeochem Cy, 23, doi:10.1029/2008gb003349.

Haine, T.W.N., Hall, T.M., (2002), A generalized transport theory: water-mass composition and age. Journal of Physical Oceanography, 32, 1932-1946. 
Haine, T. W. N., and K. J. Richards (1995), The influence of the seasonal mixed layer on oceanic uptake of CFCs, Journal of Geophysical Research: Oceans, 100(C6), 10727-10744, doi:10.1029/95JC00629.

Hall, T. M., and R. A. Plumb (1994), Age as a diagnostic of stratospheric transport, Journal of Geophysical Research-Atmospheres, 99(D1), 1059-1070, doi:10.1029/93jd03192.

Hall, T. M., D. W. Waugh, T. W. N. Haine, P. E. Robbins, and S. Khatiwala (2004), Estimates of anthropogenic carbon in the Indian Ocean with allowance for mixing and time-varying air-sea CO2 disequilibrium, Global Biogeochem Cy, 18(1), doi:10.1029/2003gb002120.

Holzer, M., and F. W. Primeau (2010), Improved constraints on transit time distributions from argon 39: A maximum entropy approach, J. Geophys. Res., 115, C12021, doi:10.1029/2010JC006410.

Holzer, M., F. W. Primeau, W. M. Smethie Jr., and S. Khatiwala (2010), Where and how long ago was water in the western North Atlantic ventilated? Maximum entropy inversions of bottle data from WOCE line A20, J. Geophys. Res., 115, C07005, doi:10.1029/2009JC005750.

Huhn O, Rhein M, Hoppema M, van Heuven S., (2013), Decline of deep and bottom water ventilation and slowing down of anthropogenic carbon storage in the Weddell Sea, 1984-2011. Deep Sea Res. I: 76, 66-84., doi:10.1016/j.dsr.2013.01.005

Ito, T., J. Marshall, and M. Follows (2004), What controls the uptake of transient tracers in the Southern Ocean?, Global Biogeochem Cy, 18(2), doi:10.1029/2003GB002103.

Jenkins, W. J. (1977), Tritium-Helium Dating in the Sargasso Sea: A Measurement of Oxygen Utilization Rates, Science, 196(4287), 291-292, doi:10.1126/science.196.4287.291.

Khatiwala, S., F. Primeau, and T. Hall (2009), Reconstruction of the history of anthropogenic CO2 concentrations in the ocean, Nature, 462(7271), 346-U110, doi:10.1038/nature08526.

Khatiwala, S., M. Visbeck, and P. Schlosser (2001), Age tracers in an ocean GCM, Deep-Sea Research Part I-Oceanographic Research Papers, 48(6), 1423-1441, doi:10.1016/s09670637(00)00094-7.

Klatt, O., W. Roether, M. Hoppema, K. Bulsiewicz, U. Fleischmann, C. Rodehacke, E. Fahrbach, R. F. Weiss, and J. L. Bullister, (2002), Repeated CFC sections at the Greenwich Meridian in the Weddell Sea, J. Geophys. Res., 107(C4), 3030, doi:10.1029/2000JC000731. 
Large, W. G., J. C. Mcwilliams, and S. C. Doney (1994), Oceanic Vertical Mixing - a Review and a Model with a Nonlocal Boundary-Layer Parameterization, Rev Geophys, 32(4), 363-403, doi:Doi 10.1029/94rg01872.

Lee, T., and I. Fukumori (2003), Interannual-to-decadal variations of tropical-subtropical exchange in the Pacific Ocean: Boundary versus interior pycnocline transports, $J$ Climate, 16(24), 4022-4042, doi:10.1175/1520-0442(2003)016<4022:ivotei>2.0.co;2.

Lee, T., I. Fukumori, D. Menemenlis, Z. F. Xing, and L. L. Fu (2002), Effects of the Indonesian Throughflow on the Pacific and Indian oceans, J Phys Oceanogr, 32(5), 1404-1429, doi:10.1175/1520-0485(2002)032<1404:eotito>2.0.co;2.

Maltrud, M., F. Bryan, and S. Peacock (2010), Boundary impulse response functions in a century-long eddying global ocean simulation, Environmental Fluid Mechanics, 10(1-2), 275 295, doi:10.1007/s10652-009-9154-3.

Marshall, J., A. Adcroft, C. Hill, L. Perelman, and C. Heisey (1997a), A finite-volume, incompressible Navier Stokes model for studies of the ocean on parallel computers, J Geophys Res-Oceans, 102(C3), 5753-5766, doi:10.1029/96jc02775.

Marshall, J., C. Hill, L. Perelman, and A. Adcroft (1997b), Hydrostatic, quasi-hydrostatic, and nonhydrostatic ocean modeling, J Geophys Res-Oceans, 102(C3), 5733-5752, doi:10.1029/96jc02776.

Mecking, S., M. J. Warner, C. E. Greene, S. L. Hautala, and R. E. Sonnerup (2004), Influence of mixing on CFC uptake and CFC ages in the North Pacific thermocline, J Geophys Res-Oceans, 109(C7), doi:10.1029/2003jc001988.

Mikaloff-Fletcher, S. E., et al. (2006), Inverse estimates of anthropogenic CO2 uptake, transport, and storage by the ocean, Global Biogeochem Cy, 20(2), doi:10.1029/2005gb002530.

Peacock, S., and M. Maltrud (2006), Transit-time distributions in a global ocean model, $J$ Phys Oceanogr, 36(3), 474-495, doi:10.1175/jpo2860.1.

Primeau, F. W., and M. Holzer (2006), The ocean's memory of the atmosphere: Residence-time and ventilation-rate distributions of water masses, J Phys Oceanogr, 36(7), 1439-1456, doi:10.1175/jpo2919.1. 
Qu, T. D., S. Gao, and I. Fukumori (2013), Formation of salinity maximum water and its contribution to the overturning circulation in the North Atlantic as revealed by a global general circulation model, J Geophys Res-Oceans, 118(4), 1982-1994, doi:10.1002/jgrc.20152.

Redi, M. H. (1982), Oceanic Isopycnal Mixing by Coordinate Rotation, J Phys Oceanogr, 12(10), 1154-1158, doi:10.1175/1520-0485(1982)012<1154:OIMBCR $>2.0 . C O ; 2$.

Sabine, C. L., et al. (2004), The oceanic sink for anthropogenic CO2, Science, 305(5682), 367371, doi:10.1126/science.1097403.

Sonnerup, R. E., S. Mecking, and J. L. Bullister (2013), Transit time distributions and oxygen utilization rates in the Northeast Pacific Ocean from chlorofluorocarbons and sulfur hexafluoride, Deep-Sea Research Part I-Oceanographic Research Papers, 72, 61-71, doi:10.1016/j.dsr.2012.10.013.

Sonnerup, R. E., S. Mecking, J. L. Bullister, and M. J. Warner (2015), Transit time distributions and oxygen utilization rates from chlorofluorocarbons and sulfur hexafluoride in the Southeast Pacific Ocean, J Geophys Res-Oceans, 120(5), 3761-3776, doi:10.1002/2015jc010781.

Stanley, R. H. R., S. C. Doney, W. J. Jenkins, and D. E. Lott (2012), Apparent oxygen utilization rates calculated from tritium and helium-3 profiles at the Bermuda Atlantic Time-series Study site, Biogeosciences, 9(6), 1969-1983, doi:10.5194/bg-9-1969-2012.

Steinfeldt, R., and M. Rhein (2004), Spreading velocities and dilution of North Atlantic Deep Water in the tropical Atlantic based on CFC time series, J. Geophys. Res., 109, C03046, doi:10.1029/2003JC002050.

Tanhua . . . ones . eansson . utterstro , W. M. Smethie Jr., D. W. R. Wallace, and L. G. Anderson (2009), Ventilation of the Arctic Ocean: Mean ages and inventories of anthropogenic CO2 and CFC-11, J. Geophys. Res., 114, C01002, doi:10.1029/2008JC004868.

anhua . . o rt i nger, K. Friis, D. W. Waugh, and D. W. R. Wallace (2007), An estimate of anthropogenic $\mathrm{CO} 2$ inventory from decadal changes in ocean carbon content, Proc. Natl. Acad. Sci., 104, 3037-3042, doi:10.1073/pnas.0606574104.

Wang, O., I. Fukumori, T. Lee, and G. C. Johnson (2004), Eastern equatorial Pacific Ocean T-S variations with El Nino, Geophys Res Lett, 31(4), doi:10.1029/2003gl019087. 
Wanninkhof, R. (1992), Relationship between Wind-Speed and Gas-Exchange over the Ocean, $J$ Geophys Res-Oceans, 97(C5), 7373-7382, doi:Doi 10.1029/92jc00188.

Warner, M. J., J. L. Bullister, D. P. Wisegarver, R. H. Gammon, and R. F. Weiss (1996), Basinwide distributions of chlorofluorocarbons CFC-11 and CFC-12 in the north Pacific: 1985-1989, $J$ Geophys Res-Oceans, 101(C9), 20525-20542, doi:10.1029/96jc01849.

Warner, M. J., and R. F. Weiss (1985), Solubilities of chlorofluorocarbons 11 and 12 in water and seawater, Deep Sea Research Part A. Oceanographic Research Papers, 32(12), 1485-1497, doi:10.1016/0198-0149(85)90099-8.

Waugh, D. W., T. M. Hall, and T. W. N. Haine (2003), Relationships among tracer ages, $J$ Geophys Res-Oceans, 108(C5), doi:10.1029/2002jc001325.

Waugh, D. W., T. M. Hall, and T. W. N. Haine (2004), Transport times and anthropogenic carbon in the subpolar North Atlantic Ocean, Deep Sea Res., Part I, 51, 1471-1491, doi:10.1016/j.dsr.2004.06.011.

Waugh, D. W., T. M. Hall, B. I. McNeil, R. Key, and R. J. Matear (2006), Anthropogenic CO2 in the oceans estimated using transit time distributions, Tellus Series B-Chemical and Physical Meteorology, 58(5), 376-389, doi:10.1111/j.1600-0889.2006.00222.x.

Waugh, D. W., F. Primeau, T. DeVries, and M. Holzer (2013), Recent Changes in the Ventilation of the Southern Oceans, Science, 339(6119), 568-570, doi:10.1126/science.1225411.

Wunsch, C., P. Heimbach, R. M. Ponte, I. Fukumori, and E.-G. C. Members (2009), The global general circulation of the oceans estimate by the ECCO-Consortium, Oceanography, 22(2), 88103.

Yamagishi, H., N. Yoshida, S. Toyoda, B. N. Popp, M. B. Westley, and S. Watanabe (2005), Contributions of denitrification and mixing on the distribution of nitrous oxide in the North Pacific, Geophys Res Lett, 32(4), doi:10.1029/2004g1021458. 


\section{Figure \& Table captions}

Figure 1. Meridional section of pCFC-11 in the North Pacific The distribution of pCFC-11 is compared between (a) observations from the Clivar Repeat Hydrography P16N which took place in 2006, (b) direct numerical simulation of pCFC-11 using the time-varying ECCO-JPL circulation fields sampled at the same time and location as the P16N cruise, and (c) the estimated pCFC-11 based on the convolution integral of the TTD and the atmospheric transient of pCFC-11. For (b) the model computes CFC-11 and pCFC-11 can be calculated by dividing the CFC-11 concentration by its solubility at local temperature. For (c), the TTD is calculated based on the climatological circulation fields from the ECCO-JPL product. The panel (d) shows the difference between the simulation and observation (b-a), and the panel (c) shows the difference between the convolution integral and observation (c-a). The panel (e) compares the simulation and the convolution integral (c-b).

\section{Figure 2. Meridional section of pCFC-11 in the central South Pacific The} distribution of pCFC-11 is compared between (a) observations from the Clivar Repeat Hydrography P16S which took place in 2005, (b) direct numerical simulation of pCFC-11 and (c) the estimated pCFC-11 based on the TTD method. The panel (d) shows the difference between the simulation and observation (b-a), and the panel (c) shows the difference between the convolution integral and observation (c-a). The panel (e) compares the simulation and the convolution integral (c-b). 
distribution of pCFC-11 is compared between (a) observations from the Clivar Repeat Hydrography P18 which took place in 2007, (b) direct numerical simulation of pCFC-11 and (c) the estimated pCFC-11 based on the TTD method. The panel (d) shows the difference between the simulation and observation (b-a), and the panel (c) shows the difference between the convolution integral and observation (c-a). The panel (e) compares the simulation and the convolution integral (c-b).

Figure 4. Meridional section of pCFC-11 in the North Atlantic The distribution of pCFC-11 is compared between (a) observations from the A16N which took place in 1998, (b) direct numerical simulation of pCFC-11 and (c) the estimated pCFC-11 based on the TTD method. The panel (d) shows the difference between the simulation and observation (b-a), and the panel (c) shows the difference between the convolution integral and observation (c-a). The panel (e) compares the simulation and the convolution integral (c-b).

Figure 5. TTD of the thermocline and intermediate waters TTD of Subtropical Mode Waters (STMWs) are evaluated at the location of (a) BATS and (b) HOT in the North Atlantic and North Pacific. (c) TTDs at 1,000m depth from the North Atlantic (at BATS, blue solid), North Pacific (at HOT, red dash) and the Southern Ocean (in the Drake Passage, black dash dot). (d) TTD at 1,000m depth in the North Pacific (same as panel $\mathrm{c}$ but plotted in different scales).

Figure 6. Isopycnal depth and mean age of the isopycnal surface $\left(\sigma_{\theta}=\mathbf{2 5 . 2}\right) \quad$ (a) The annual mean depth of the isopycnal surface and (b) the mean age of the isopycnal surface are plotted for 
the Pacific basin. The color shading for the mean age saturates at 30 years of age in the eastern tropical North Pacific.

Figure 7. The spread of TTD $(\Delta)$ and $(\Gamma / \Delta)$ of the isopycnal surface $\left(\sigma_{\theta}=25.2\right)$ (a) The spread of the TTD is calculated based on the second moment of the TTD. (b) the ratio $\Gamma / \Delta$ is then determined.

Table 1. Quantitative assessment of the modeled pCFC-11 distribution The observational data is objectively mapped onto the model grid. The mean bias between the modeled and observed pCFC11 (above 2,000m depth) is shown in the left two columns. The values within the parenthesis are the relative magnitude of the bias with respect to the observation. The spatial correlation coefficients are shown in the right two columns. 
a.
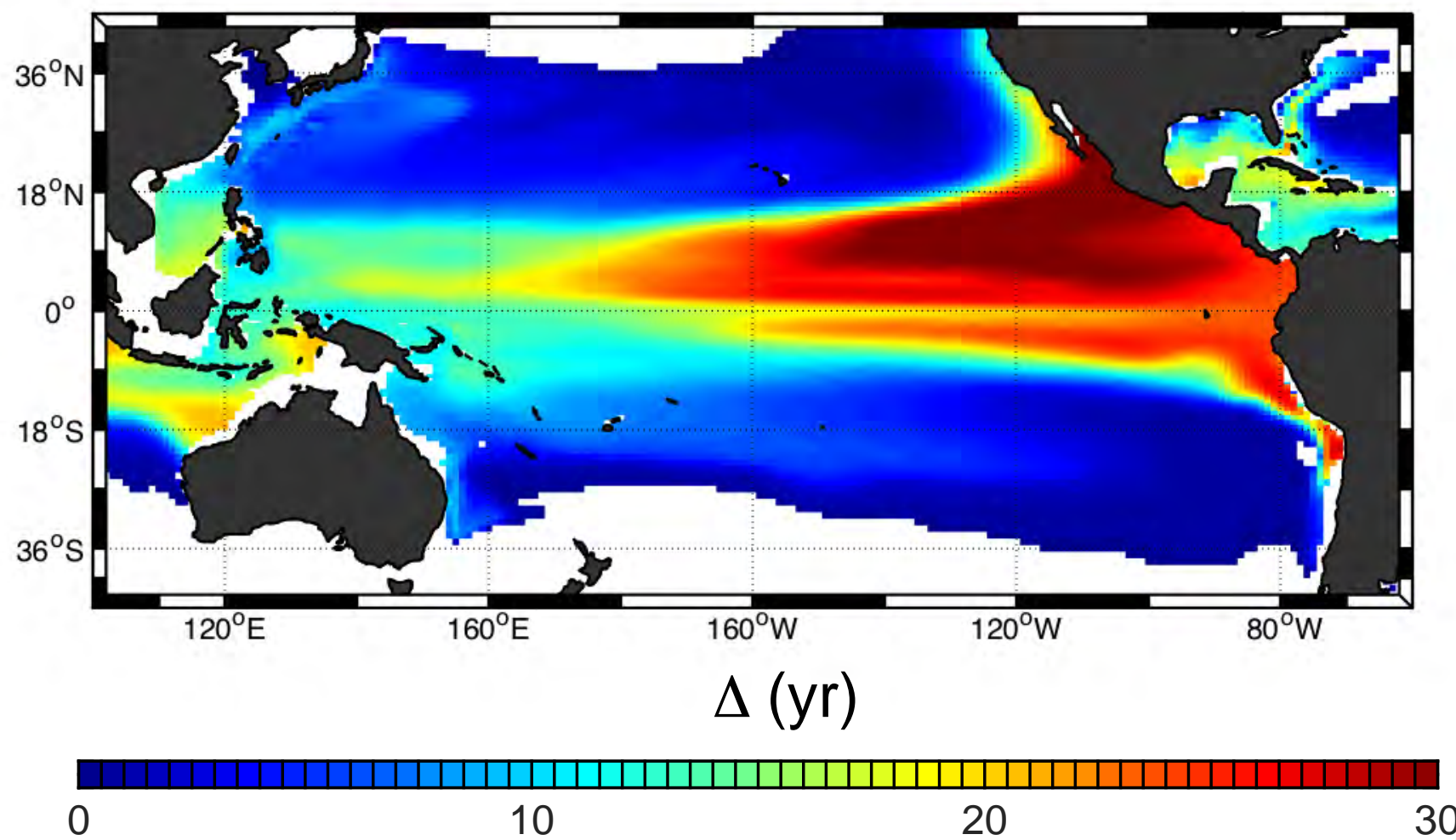

b.

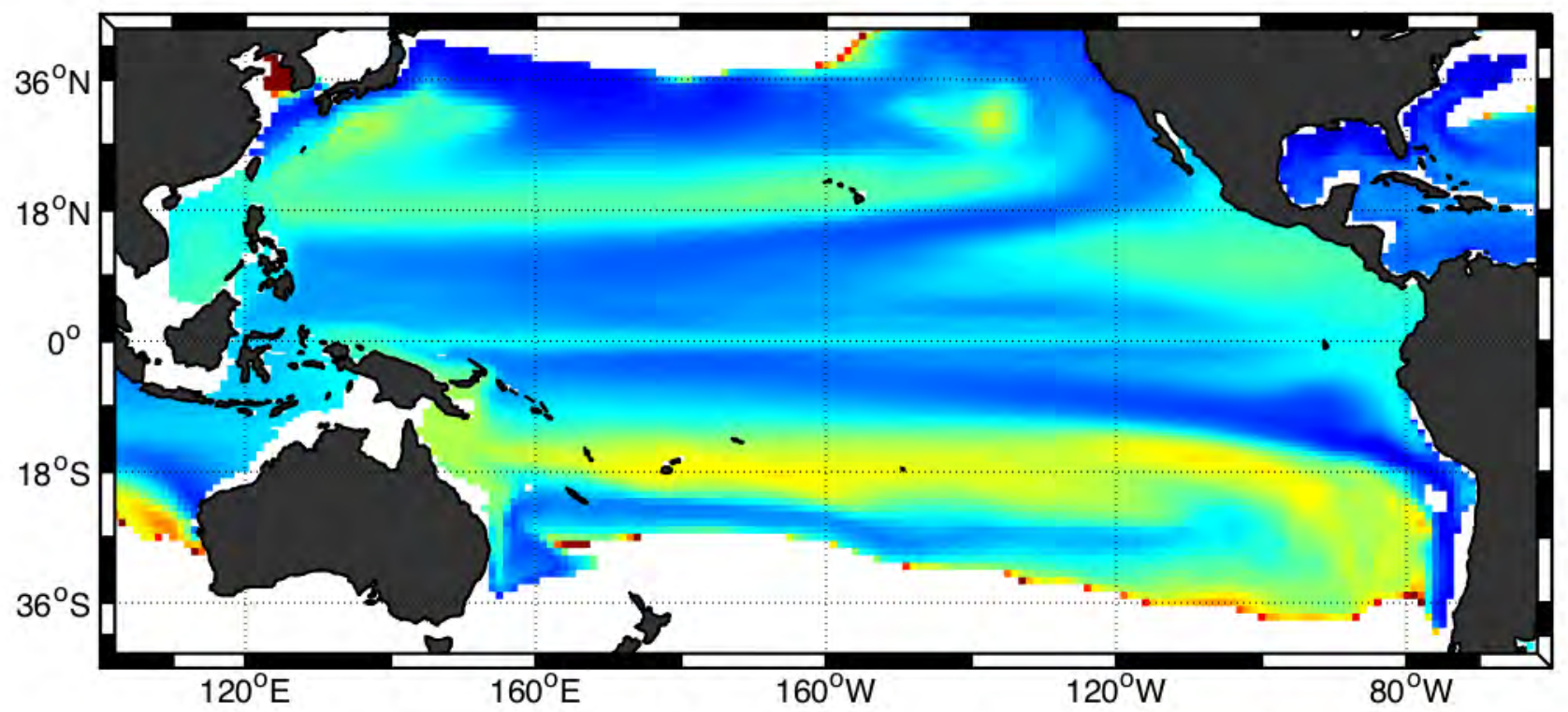

$\Gamma / \Delta$

0

1

2 
a.

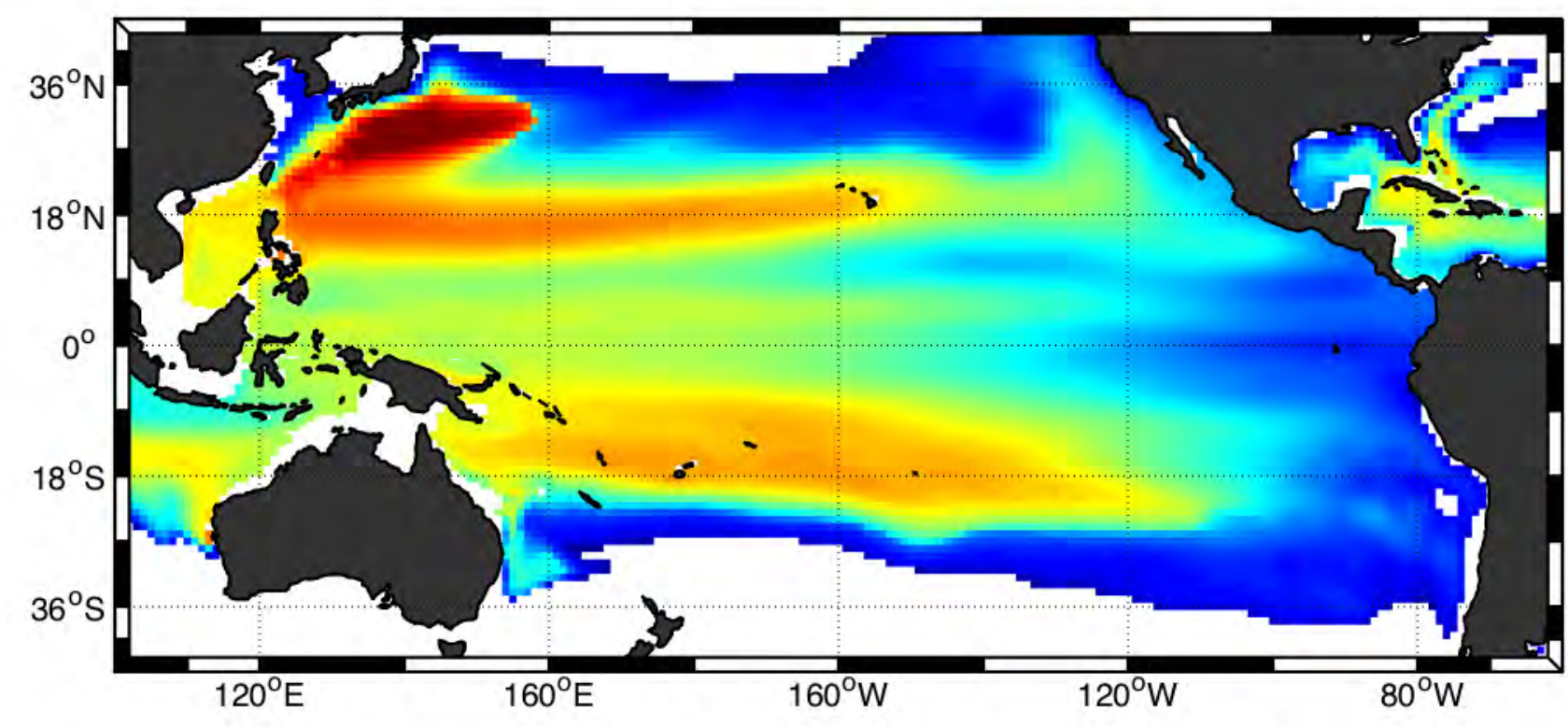

Isopycnal depth (25.2)

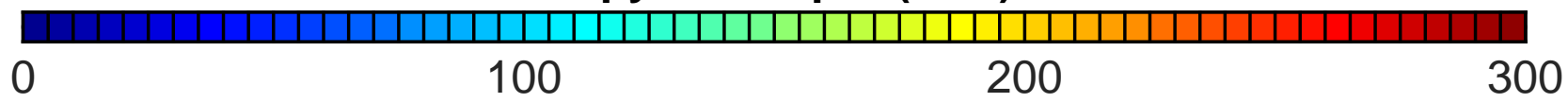

b.
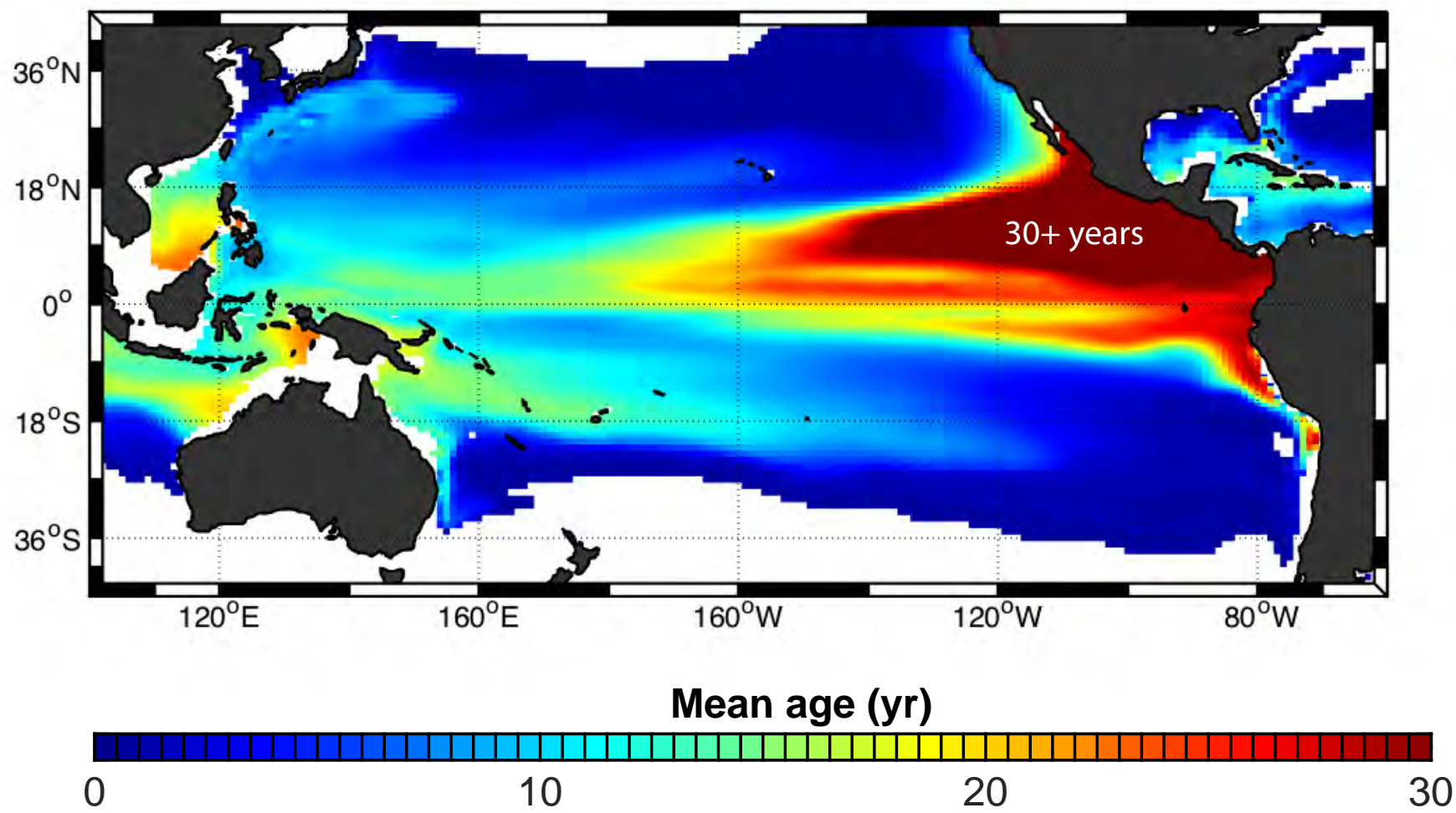
a.
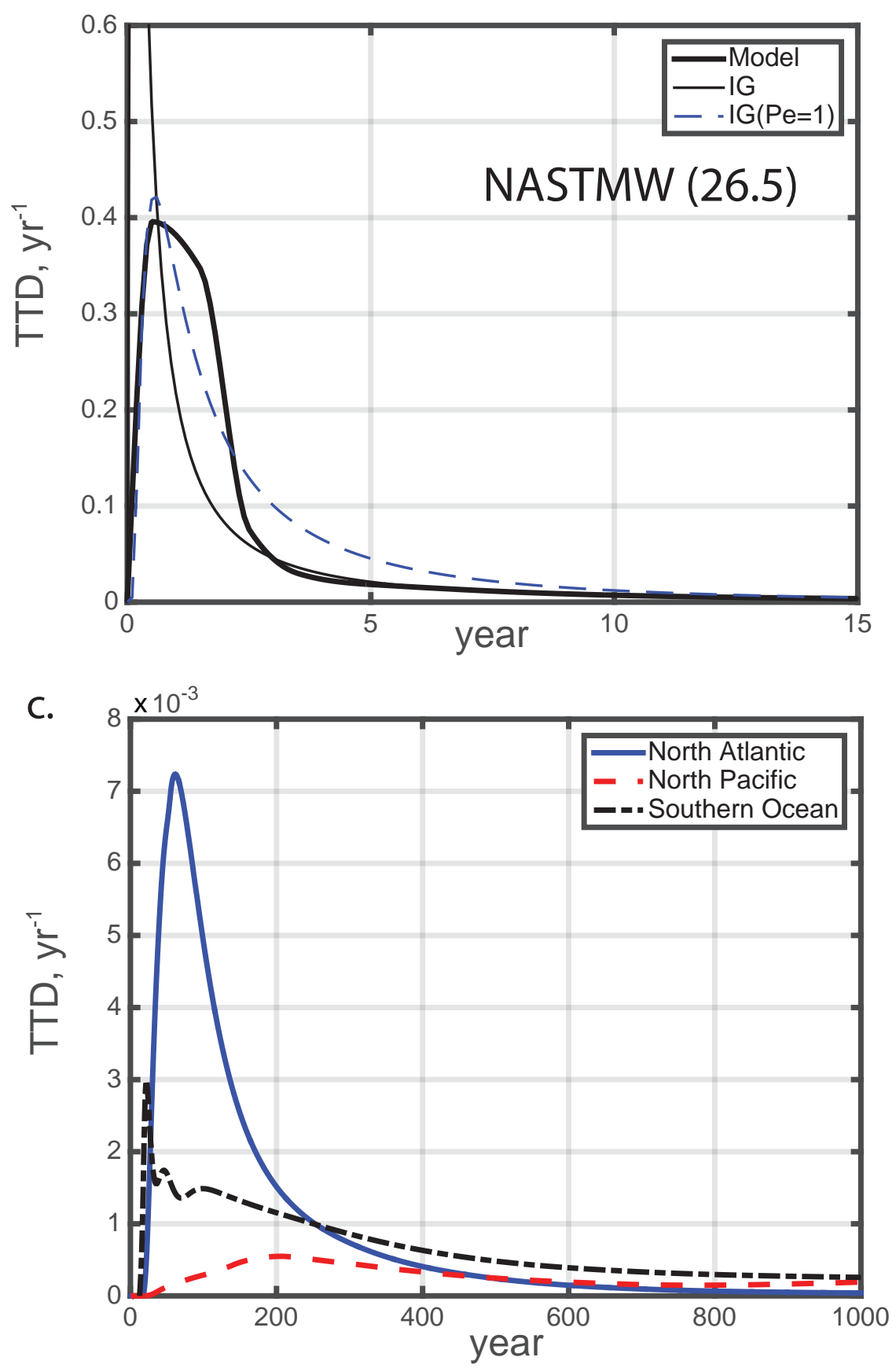

b.

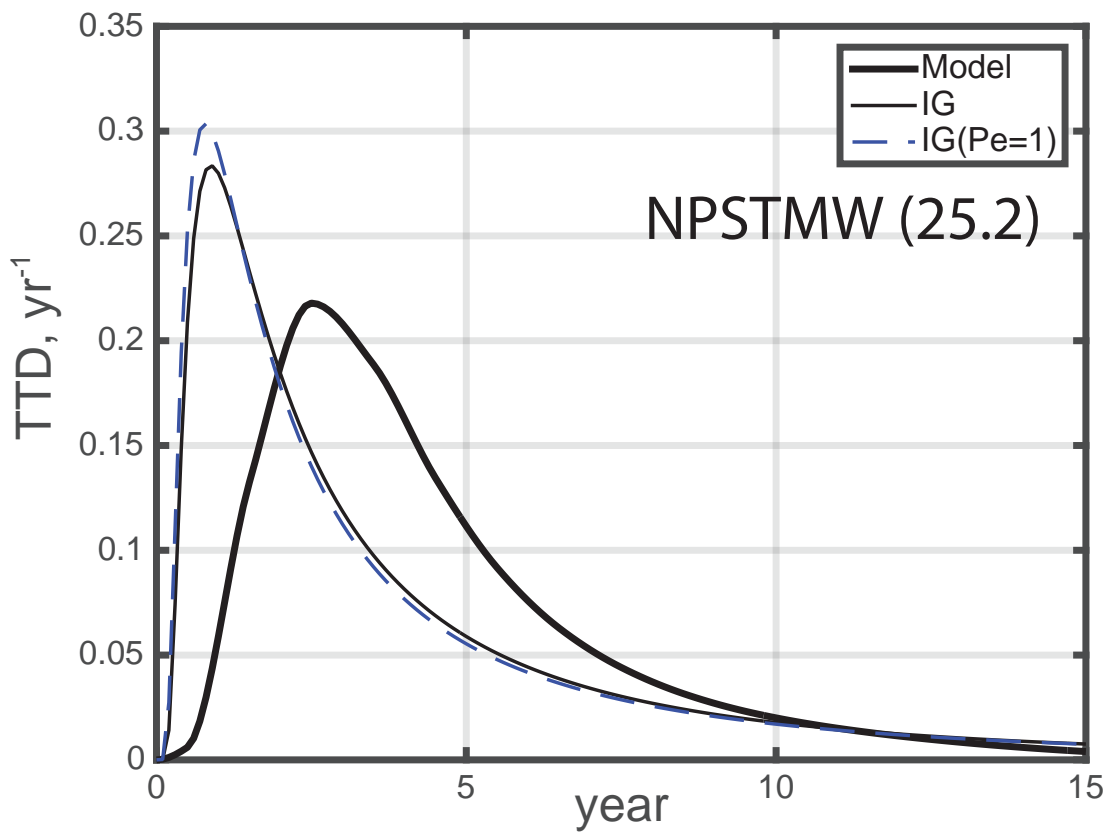

d. $6 \times 10^{-4}$

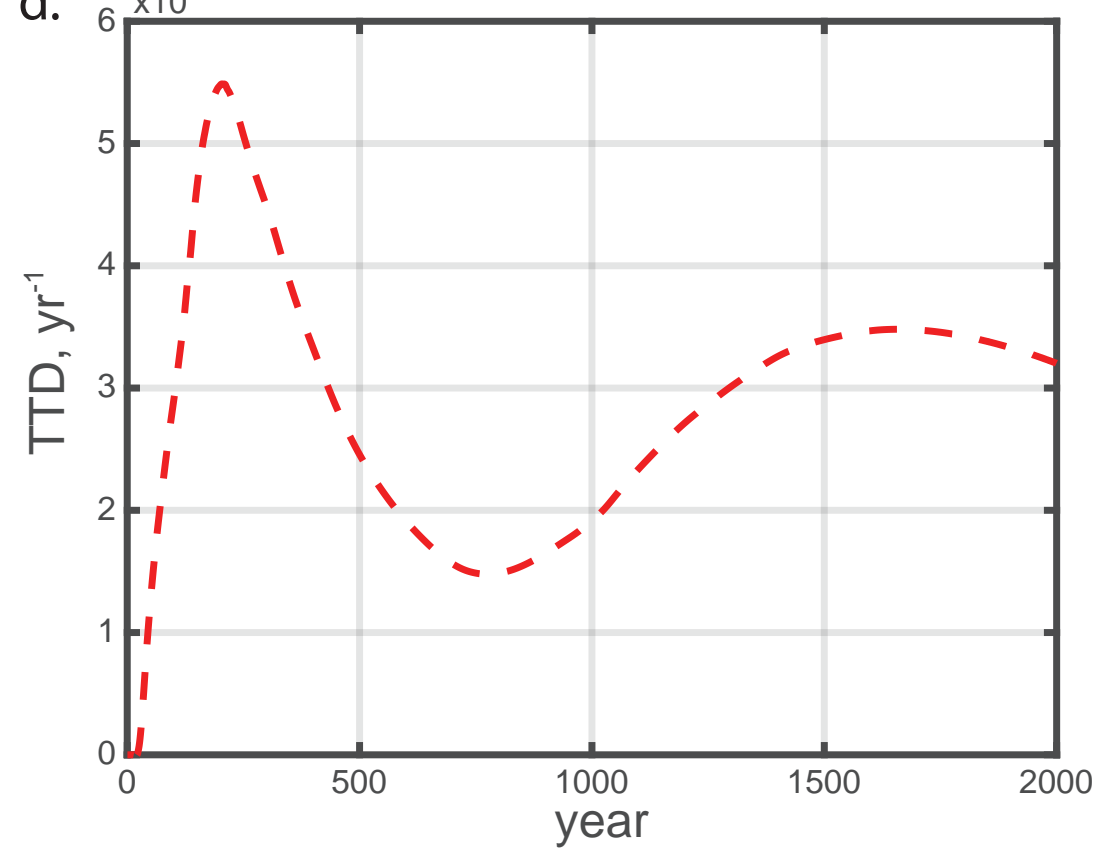



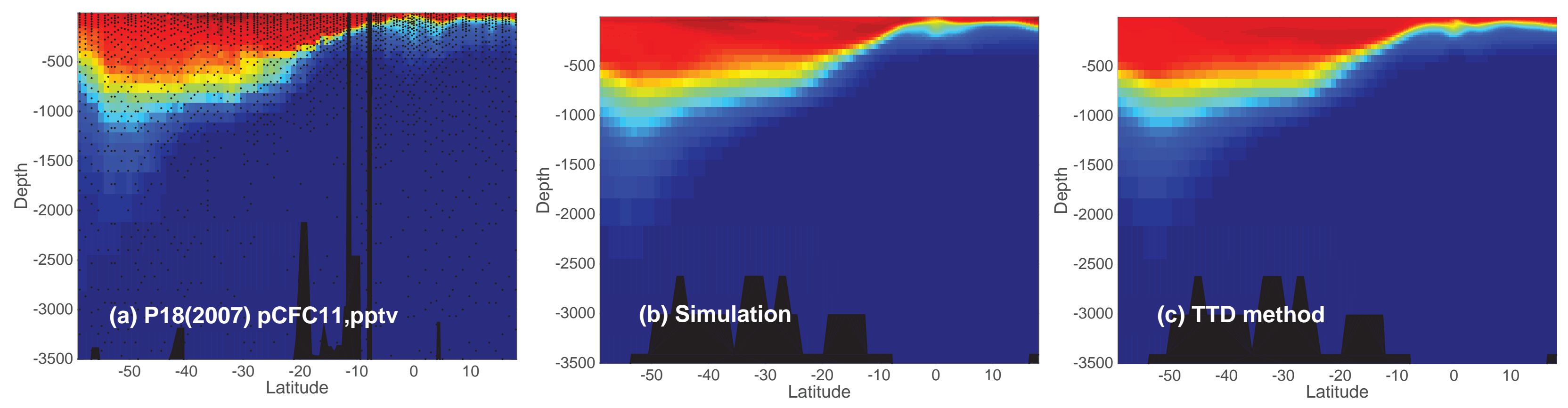

pCFC-11 pptv
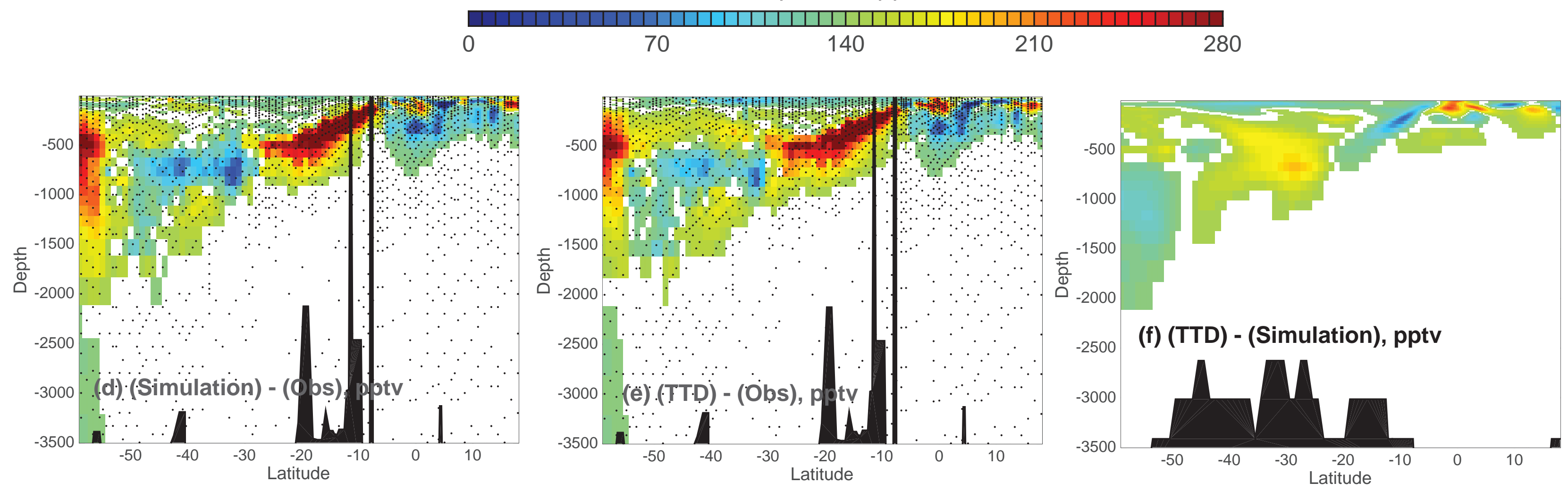

$\Delta$ pCFC-11 pptv 

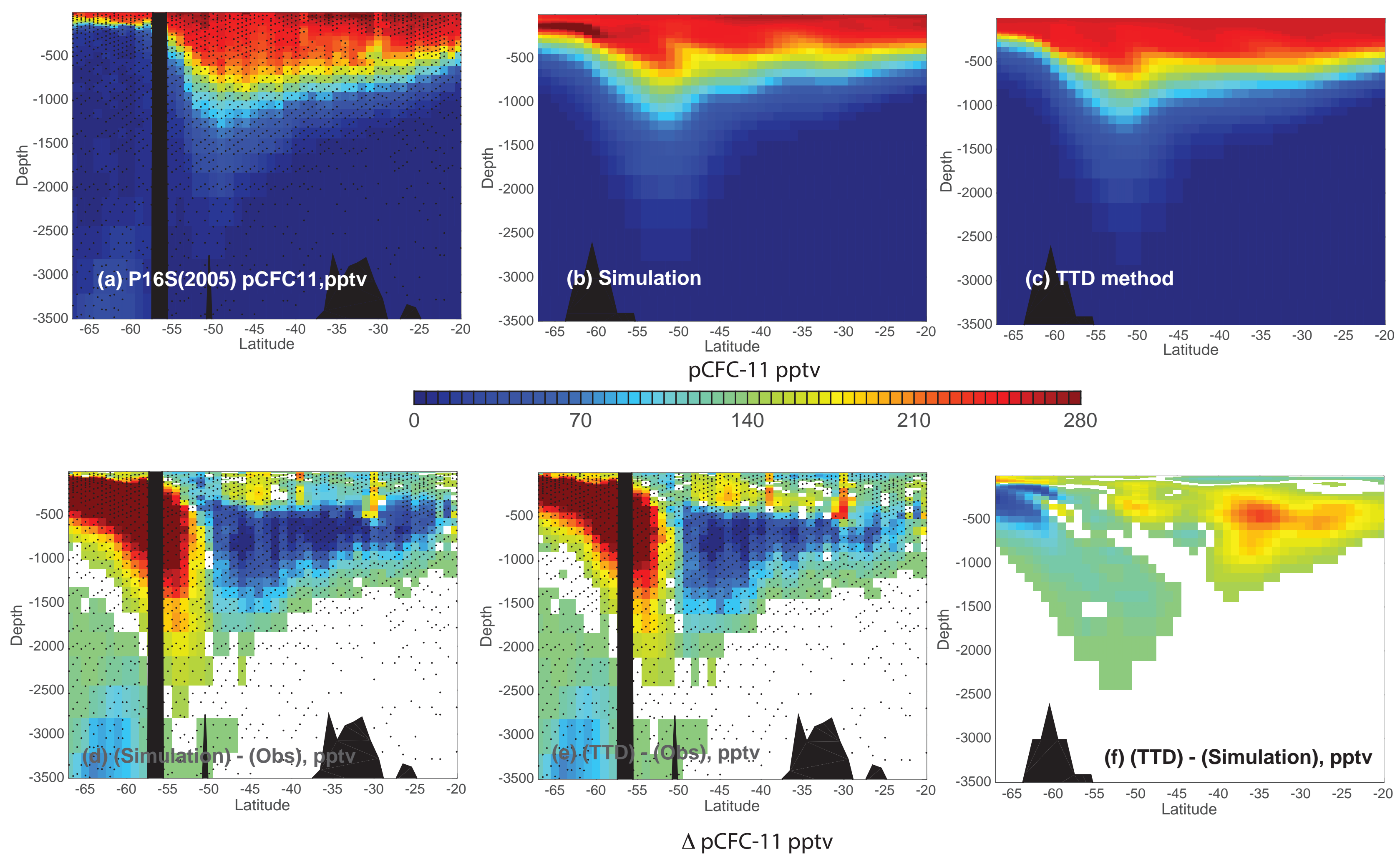

$\Delta$ pCFC-11 pptv

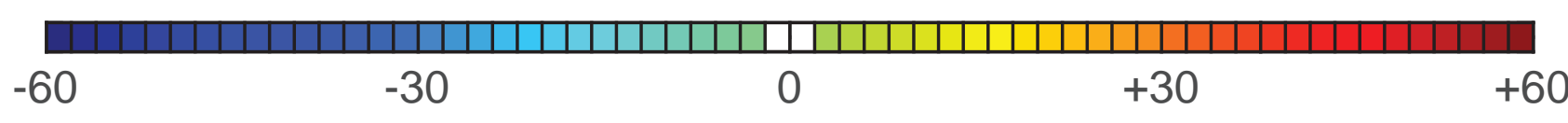


Mean bias (sim) $\quad$ Mean bias (TTD) $\quad$ Corr coeff (sim) $\quad$ Corr coeff (TTD)

\begin{tabular}{cllll}
\hline A16N & 0.14pptv (0.11\%) & 7.49pptv (5.83\%) & 0.90 & 0.88 \\
P16N & 1.60pptv (4.39\%) & 0.62pptv (1.71\%) & 0.98 & 0.98 \\
P16S & 3.42pptv (4.53\%) & 3.79pptv (5.01\%) & 0.87 & 0.90 \\
P18 & 1.26pptv (3.01\%) & 1.45pptv (3.45\%) & 0.98 & 0.98
\end{tabular}

